\title{
La garantía de la propiedad y el principio de proporcionalidad como límites de la carga tributaria en Alemania*
}

\author{
Raffael Sänger" \\ Recibido: 3 de enero de 2015 - Revisado: 8 de marzo de 2015
}

- Aprobado: 25 de abril de 2015

\section{Resumen}

Bajo el concepto superior de justicia, el artículo quiere indagar por la pregunta de cómo puede ser protegido el ciudadano en Alemania por las garantías aseguradas constitucionalmente frente a una carga tributaria desbordada. El punto central lo constituye la garantía de propiedad y el principio de proporcionalidad como mecanismo más importante de protección jurídica en un Estado de Derecho. Para el efecto, se debe encontrar un límite máximo para la carga fiscal del patrimonio respectivo, que pueda ser entendida como concreción de la garantía de la propiedad. Palabras clave: justicia, carga tributaria, garantía de la propiedad, principio de proporcionalidad.

"El proyecto de investigación por el cual se emite el presente articulo, ha sido financiado por el Servicio Alemán de Intercambio Académico (DAAD). La investigación hizo parte de los proyectos académicos del año 2013 pajo el título general "Economía y Estado".

"El autor es abogado de la Universidad de Konstanz (Alemania), Magister en Derecho Publico de la Universidad Santo Tomás (Bogotá, Colombia) y candidato a Doctor en Derecho y Asesor Jurídico Científico en la cátedra de Derecho Público del profesor Dr. Dr. h.c. Martin Ibler en la Universidad de Konstanz. Correo electrónico: raffael.saenger@uni-konstanz.de 


\title{
THE GUARANTEE OF THE PROPERTY AND THE PRINCIPLE OF PROPORTIONALITY AS BOUNDARY OF TAX BURDEN IN GERMANY
}

\begin{abstract}
Under the superior concept of justice, the article aims to investigate on the question of how citizens can be protected in Germany by the guarantees constitutionally ensured against an overwhelming tax burden. The central issue is the guarantee of property and the principle of proportionality as the most important mechanism of legal protection under the Rule of Law. For this purpose, a maximum boundary must be found for the tax burden of the respective estate, which can be understood as the realization of guarantee of the property.
\end{abstract}

Keywords: Justice, tax burden, guarantee of the property, principle of proportionality.

\section{A gaRANTIA DA PROPRIEDADE E O PRINCÍPIO DA PROPORCIONALIDADE COMO LIMITES DA CARGA tributaria na Alemanha}

\section{Resumo}

Sob o conceito superior de justiça, o artigo tem como objetivo investigar pela pergunta de como pode ser protegido o cidadão na Alemanha pelas garantias constitucionalmente asseguradas contra uma carga tributária excessiva. O ponto focal é constituído pela garantia da propriedade e do princípio da proporcionalidade, como o mecanismo mais importante de proteção jurídica num Estado de Direito. Para este efeito, deve-se encontrar um limite máximo para a carga fiscal dos respectivos ativos, o que pode ser entendido como a realização da garantia da propriedade.

Palavras-chave: Justiça, carga tributária, garantia da propriedade, princípio de proporcionalidade.

\section{Introducción}

Justicia es un concepto que no tiene sentido sin una referencia (Di Fabio, 2007, p. 749). De la palabra justicia no puede derivarse una comprensión vinculante, con validez general para la misma. Solo a través de un punto de referencia concreto 
parece posible darle contornos al concepto (Rüthers, 2009, p. 174). Para el ciudadano respetuoso de las leyes, la carga tributaria representa quizá uno de los puntos de conexión más significativos que plantea la pregunta por la justicia en la relación entre el ciudadano y el Estado.

En todo caso, la simple utilización de los conceptos impuestos y justicia en una misma frase requiere ya un cuidado especial. El libro Demonio Impuesto publicado en el área de habla alemana en 1956 y su subtítulo Un calvario de la humanidad dan una pista sobre esto (Pirnat, 1956). En el libro el autor expone todas las posibles desviaciones de la tributación que han surgido en la larga historia de los Estados. Como puede verse, el anhelo de la humanidad por una justicia tributaria no pudo impedir dichas desviaciones (Birk, 2011, pp. 354-364).

Los padres de la Ley Fundamental (LF) preservaron el cuidado recién mencionado, pues contrario a la Constitución de la República de Weimar, la LF no contiene declaraciones sobre la repartición de la carga tributaria, y mucho menos un mandato expreso de producción de justicia tributaria.

Sin embargo, ya en 1976 el Tribunal Constitucional Federal no tuvo muchas dificultades para derivar de la Constitución un "mandato fundamental de justicia tributaria”, el cual se caracteriza por la tributación según la capacidad productiva (económica) (Tribunal Constitucional Federal, tomo 82, pp. 60-86). En el interés de la igualdad de cargas tributarias mandada por el derecho constitucional, se debería apuntar a que los contribuyentes con capacidad productiva tributen igualmente, mientras que los gravámenes de los ingresos altos, en comparación con la carga tributaria de los ingresos bajos, deben satisfacer el mandato de justicia. E1 Tribunal Constitucional Federal habla de justicia tributaria "horizontal" y "vertical" (Tribunal Constitucional Federal, tomo 82, pp. 60-89). En numerosas decisiones el Tribunal ha transformado y concretado esta posición a los casos específicos. Así, el principio de la capacidad productiva se ha convertido en un postulado de la justicia tributaria en virtud del carácter vinculante de la jurisprudencia constitucional.

Sin embargo, el principio de capacidad productiva no cierra, ni mucho menos, todas las lagunas de justicia del Estado impositivo. Por ejemplo, la cuestión de si la potestad impositiva estatal está sometida a límites máximos de gravamen, queda sin respuesta. En tiempos en los que el Estado asume cada vez más tareas, esta problemática gana cada vez más importancia, puesto que el Estado recurre para la financiación de sus actividades en cantidades considerables a los recursos y el patrimonio de sus ciudadanos. Así, los ingresos por recaudo de impuestos en Alemania en el año 2012 
fueron cerca de 600 billones de euros, comparados con cerca de 10 billones en 1950 . Las cargas impositivas son la consecuencia de una concentración de funciones y una sobrecarga de tareas en cabeza del Estado (Papier, 1987, p. 146; DVBI, 1980, p. 797). En especial la ampliación del Estado Social moderno conduce al peligro de una carga exagerada de la esfera del patrimonio privado por medio de los impuestos (Rodi, p. 93). A estas cargas presupuestarias crecientes y conocidas hace décadas se suman las obligaciones que la República Federal de Alemania ha asumido en la forma de garantías para la estabilización de la unión monetaria europea. En el peor de los casos, según el estado actual, tendría que contarse con obligaciones de pago que ascenderían a casi 400 billones de euros ${ }^{1}$. No menos importante, las amplias expectativas de configuración económicas y de política social que recaen sobre el derecho tributario, contribuyen al crecimiento de la carga fiscal por la sobre-extensión de funciones (Papier, 1987, p. 141; Klein, p. 238).

Una carga fiscal excesiva tiene consecuencias financieras, económicas y políticas graves para el ciudadano y la economía (Schemmel, 1992, p. 83). Ella frena la disposición productiva y de inversión de los contribuyentes y conduce a una migración a la economía paralela y a países con menor carga de impuestos. En la medida en que las altas cargas tributarias repercutan en los precios y salarios, contribuyen a las pérdidas de puestos de trabajo y a la disminución del crecimiento y representan una carga para los presupuestos públicos (Seillhorn, 2011, p. 87). Ante todo, los altos costos laborales vinculados con el nivel de impuestos en Alemania generan una carga considerable para las empresas. Un cambio de la base de los negocios al extranjero se vuelve una alternativa para muchas de ellas. Los impuestos excesivos no solo generan un desplome de los estímulos para invertir y una fuga de capitales, sino que inducen a la evasión de impuestos, o por lo menos a la elusión. Además, la alienación de la política vinculada con la alta carga impositiva brinda un motivo para fijar un límite a la potestad impositiva desde un punto de vista cuantitativo.

Confiar esto a los parlamentos promete un éxito reducido. Pues estos prácticamente ya no cumplen con su función de impedir el exceso de erogaciones y de frenos a los gastos, por el contrario se han convertido en aceleradores de los mismos (Kirchhof, 1984, pp. 149-151). La actual práctica de los representantes popularmente elegidos ha promovido incluso la puesta en peligro de la propiedad por la tributación a través del creciente uso de los impuestos para el diseño social y para

\footnotetext{
${ }^{1}$ Disponible en http://www.handelsblatt.com/politik/international/euro-rettung-koennte-zumbillionen-risiko-werden/5249660.html?p5249660=all
} 
la dirección de la economía. La sociedad ha dirigido expectativas de prestaciones tan altas hacia el Estado que el parlamentario se entiende a sí mismo menos como un garante de una carga impositiva reducida y actúa más como un precursor de programas estatales asistenciales; con ello contribuye al constante aumento de la carga impositiva. Sin embargo, entre más acerque el legislador la carga tributaria al límite máximo, más debe probar su eficacia el derecho constitucional tributario frente a este legislador. La inflación de las tareas estatales indica entonces la necesidad de reglas para la limitación de la participación estatal y la fundamenta sobre causas esenciales.

El presente aporte no tiene la pretensión de abrir un gran debate sobre la justicia tributaria. Aquí simplemente se quiere, bajo el concepto superior de la justicia, indagar por la pregunta de cómo puede ser protegido el ciudadano con las garantías aseguradas constitucionalmente frente a una carga tributaria desbordada. E1 punto central lo constituyen la garantía de propiedad del artículo $14 \mathrm{LF}$, artículo 14 de la Ley Fundamental de la República Federal de Alemania: Inciso primero: "La propiedad y el derecho a la herencia están garantizados. Su contenido y sus límites serán determinados por las leyes". Inciso segundo: "La propiedad obliga. Su uso debe servir al mismo tiempo al bien común”. El principio de proporcionalidad como mecanismo más importante de protección jurídica en un Estado de Derecho. Se debe encontrar un límite máximo para la carga fiscal del patrimonio respectivo, que pueda ser entendida como concreción de la garantía de la propiedad.

\section{La garantía de la propiedad frente a la potestad impositiva}

\section{La garantía de propiedad del artículo $14 \mathrm{LF}$}

a. La propiedad como garantía de una forma de vida autorresponsable en su aspecto económico

La propiedad es un derecho fundamental elemental (Tribunal Constitucional Federal, tomo 102, pp.1-15). Como decisión valorativa del constituyente de especial importancia para el Estado Social de Derecho (Ibídem, tomo 102, pp. 1-15), la garantía de la propiedad se encuentra en una estrecha relación con la garantía de la libertad personal (Ibídem, tomo 24, pp. 367-384). y asegura el fundamento 
económico de disposición privada para la libertad individual (Ibídem, tomo 97, pp. 350-370). La propiedad constitucional se caracteriza por el uso privado y la facultad de disposición del propietario sobre el objeto de la propiedad. Debe servirle al propietario como base de la iniciativa privada y debe ser útil para la iniciativa y el interés privado autorresponsable (Ibídem, tomo 102, pp. 1-15). El objetivo primario de la garantía de propiedad consiste en proteger el interés privado del propietario, la disposición de su patrimonio y la libertad reificada en ella; la propiedad es "autonomía privada acumulada" (Isensee, HStR VII, § 150, número marginal 64; cfr. también el mismo autor, HStR IX, § 190, número marginal 213).

$\mathrm{El}$ derecho fundamental de la propiedad tiene que servir al aseguramiento de la libertad personal en tanto protege las condiciones económicas para ella (Schachtschneider, 1994, p. 754; Limpens, 1973, p. 155). La conexión entre libertad y propiedad consiste, según esto, en que la propiedad constituye un requisito de ámbitos esenciales de la libertad (Schachtschneider, 1994, p. 766; Depenheuer, 1999, p. 278). El derecho fundamental de la propiedad facilita el ejercicio de otros derechos de libertad (Limpens, 1973, p. 60). Para el individuo la propiedad es un seguro material de existencia, independencia y libertad. La propiedad, como condición del Estado moderno hace posible la independencia del ciudadano de este Estado y facilita que los titulares de los derechos fundamentales tengan la posibilidad de ejercitar efectivamente su libertad (Depenheuer, 1999, p. 279). Por medio del énfasis de la tarea de una protección que flanquea la garantía de la libertad se aclara la necesidad irrenunciable de una garantía efectiva de la propiedad.

b. El significado de la determinación de contenido y límites de la garantía de la propiedad

El concepto de propiedad del artículo $14 \mathrm{LF}$ parte de que la propiedad no existe como un derecho natural sino que se desprende de una creación del ordenamiento jurídico. Así, la Ley Fundamental en el artículo 14 inciso primero frase segunda le confirió expresamente al legislador ordinario la tarea de regular el contenido y los límites de la propiedad. Conforme a esto el legislador ordinario tiene que garantizar el estado actual de derechos con valor patrimonial como el ámbito de protección determinante del derecho fundamental de propiedad (ámbito de protección determinado por norma) (en alemán: Normgeprägter Schutzbereich, p. 643). Estas 
normas concretan los derechos y los deberes del propietario, así como el contenido total de la propiedad.

El contenido y los límites se entienden así como un par conceptual con contenido significativo idéntico y con un mandato de regulación igual para el legislador ordinario (Schachtschneider, 1994, p. 823).. Bajo una determinación conforme al artículo 14 inciso primero frase segunda LF se entiende toda fijación de derechos y deberes por parte del legislador con respecto a los bienes jurídicos que deben entenderse como propiedad en el sentido de la Constitución (Tribunal Constitucional Federal, tomo 52, pp. 1-27). Conforme a ello, esta tarea se dirige a la creación de preceptos de derecho objetivo que regulen de manera general hacia el futuro el contenido del derecho de propiedad.

Del hecho de que no existe un concepto estático de la propiedad se sigue que el ámbito de protección de la garantía de propiedad debe ser concretado por medio del ordenamiento jurídico (Ibídem, tomo 20, pp. 351-355; tomo 24, p.p. 367-396; tomo 31, pp. 229-240; tomo 53, pp. 257-292). Por lo tanto, la dependencia del legislador ordinario resulta precisamente de que no se le puede asignar un contenido conceptual a la propiedad constitucional, sino que las posibilidades individuales de actuación deben configurarse en detalle por el ordenamiento jurídico. La propiedad requiere forzosamente ser formulada (jurídicamente) como objeto del derecho fundamental para ser reconocida como tal en el ordenamiento jurídico (Schachtschneider, 1994, p. 765). A diferencia de las reservas de ley y de regulación ordinarias, aquí el legislador no interviene reglamentando para la protección de intereses del bien común en un ámbito de la vida social. Por el contrario, el ordenamiento de la propiedad en su totalidad es formulado por él. La propiedad depende conceptualmente de la ley en sentido general; solo existe propiedad conforme a la ley (Ibídem).

No obstante, la barrera de las determinaciones de contenido y límites siempre es la garantía constitucional de la propiedad; es decir, la réplica legislativa del concepto constitucional de propiedad no determina el objeto sino las correcciones marginales admisibles de la garantía constitucional (Kirchhof, 1984, p. 21). Incluso conforme al principio de prevalencia de la Constitución el concepto de propiedad del artículo 14 inciso primero LF tiene un contenido autónomo (Böhmer, 1988, p. 2.571). Con el concepto "propiedad" la Constitución delimita el objeto de protección del artículo $14 \mathrm{LF}$ de manera definitiva y suficiente (Leisner, HbStR VI, $§ 149$, número marginal 72). De las normas del derecho ordinario, que se encuentran en un rango inferior a la Constitución, no puede derivarse un concepto 
de propiedad en el sentido constitucional, ni puede determinarse de su posición en el derecho privado el alcance de la garantía de la propiedad respectiva de manera definitiva (Tribunal Constitucional Federal, tomo 58, pp. 300-335). Conforme a esto, el concepto de propiedad de la LF no puede extraerse del derecho legal ordinario. Solo del contenido constitucional de la propiedad se obtiene cómo deben formularse legislativamente las especificidades de la propiedad, lo cual constituye posteriormente el objeto de la garantía de la propiedad (Leisner, HbStR VI, § 149, número marginal 72).

\section{La apertura del ámbito de protección del artículo 14 LF por medio de la carga tributaria}

La propiedad en el sentido del artículo $14 \mathrm{LF}$ es la suma de los derechos patrimoniales garantizados por el legislador (Tribunal Constitucional Federal, tomo 105, pp. 252-277-; tomo 95, pp. 267-300). De estos hacen parte típicamente la propiedad sobre bienes muebles e inmuebles, los derechos reales como hipotecas, créditos reales y prendas, la libertad de construcción, los derechos de marcas, patentes y de autor y el derecho de sucesión, para nombrar solo algunos de los objetos de protección. Para delimitar, la libertad de profesión consagrada en el artículo 12 LF (libertad de profesión) protege la actividad productiva misma, por el contrario, la garantía de propiedad protege lo producido, el resultado de una actividad (Ibídem, tomo 88, pp. 366-377; tomo 105, pp. 252-264).

Del hecho que el ámbito de protección esté determinado por normas, se desprende además que no se protege el patrimonio como tal, es decir, a través del artículo $14 \mathrm{LF}$ no se puede proteger la totalidad de dinero y bienes avaluables en dinero que reúna una persona, sino los derechos patrimoniales individualmente considerados (Ibídem, tomo 91, pp. 207-220; tomo 96, pp. 375-397). Como veremos a continuación, este resultado es de una importancia considerable para la pregunta de si la imposición de deberes de prestación de dinero debe medirse con la escala del artículo $14 \mathrm{LF}$. Pues sorprendentemente la doctrina y la jurisprudencia tienen respuestas diferentes sobre esta problemática.

a. Reserva (de ley) tributaria y vinculación a la Constitución (artículo 1 inciso tercero LF) 
En las décadas posteriores a la creación de la LF, reputados autores formularon una y otra vez que en el Estado impositivo la potestad de imponer impuestos debe delimitarse la protección de la propiedad como derecho fundamental (Forsthoff, 1954, p. 32; Jungnickl, p. 113; Bayer, 1981, p. 366). La necesidad de recursos y los propósitos que requieren financiación se encontrarían, según eso, por fuera del ámbito de protección de la garantía de propiedad. Si se aplicara esta distinción entre la intervención tributaria (no sujeta a límites) y la intervención en la propiedad, se eliminarían en gran medida todas las pretensiones de reparación que le quitarían el fundamento constitucional al Estado Social (Forsthoff, 1954, p. 8-32). Por el contrario, esta delimitación es un elemento fundamental del Estado Social de Derecho.

En tanto que la figura de esta reserva tributaria general como precepto constitucional no escrito sirva simplemente como argumento para que al ciudadano le puedan ser impuestas obligaciones fiscales y con ello se conciba el derecho de recaudar impuestos como tal, se puede aceptar dicha argumentación (Rüfner, 1970, p. 881). La tesis, según la cual el Estado de Derecho como Estado impositivo se basa en la delimitación de la potestad impositiva y la protección fundamental de la propiedad, es entonces acertada, en la medida en que los impuestos son hoy en día el sustento de las finanzas públicas y por lo tanto constituyen una necesidad.

Sin embargo, esto no debe conducir a que en general se niegue la protección fundamental a través del artículo $14 \mathrm{LF}$, y a que se designe a los impuestos como un deber ciudadano ilimitado. La opinión según la cual los impuestos no afectan la garantía de propiedad es una concepción liberal del Estado de Derecho que ha sido superada (Arnim, 1981, p. 290). No obstante, una reserva tributaria general limitaría las garantías de libertad formales mucho más que con reserva de ley y no haría posible un sistema de libertad económica general. La exclusión de la potestad financiera del Estado de la protección fundamental de la propiedad representaría un quebrantamiento esencial del sistema de protección estatal en su totalidad. Con la prevalencia de la recaudación fiscal ante la garantía de propiedad, las normas tributarias se convertirían en facultades de intervención materialmente ilimitadas, de esa manera la potestad financiera estatal se vería dispensada de la garantía de la propiedad como derecho fundamental (Friauf, 1980, p. 482).

La expresión determinante sobre la relevancia de la intervención impositiva para la propiedad se encuentra en el artículo 1 inciso tercero LF, que vincula todos los actos del poder público a los derechos fundamentales y con eso le ofrece 
al ciudadano protección de derechos fundamentales frente a cualquier manifestación del poder estatal. La recaudación de impuestos como expresión del poder estatal que interviene en la esfera vital y de derechos del ciudadano es controlada directamente por el artículo 1 inciso tercero LF, así como por el artículo 20 inciso tercero LF, y de esa manera es puesta bajo la responsabilidad de respeto a los derechos fundamentales y a la totalidad del ordenamiento jurídico constitucional (Schenke, 1976, p. 178). Con ello, para todos los actos soberanos de la legislación, administración y jurisprudencia y para cada clase de transferencias de dinero del ciudadano al estado ocurrida en virtud del ejercicio de soberanía resulta aplicable que la actuación estatal solo es posible en el marco de los derechos fundamentales (Reener, DStZ, 1999, p. 820).

En la LF no se encuentran puntos de apoyo para una reserva tributaria ilimitada frente a la constitución (Jungnickl, p. 116). La garantía de propiedad no pierde su obligatoriedad cuando el Estado ejerce su poder con medios de las finanzas estatales (Kirchhof, 1981, p. 280). Según esto, la legislación tributaria conforme a la Constitución, como determinación del contenido de la propiedad, tiene que respetar el artículo $14 \mathrm{LF}$ así como las decisiones valorativas fundamentales del constituyente.

\section{b. Jurisprudencia constitucional}

Según la tesis de los auxilios a la inversión del Tribunal Constitucional Federal en 1954, existía consenso acerca de que los deberes de prestaciones monetarias no pueden afectar la propiedad, puesto que el deudor tributario no debe cubrirlas del objeto económico que constituye el tipo descriptivo de la norma tributaria, sino de su patrimonio ${ }^{2}$. Así, las prestaciones monetarias precisamente no deben satisfacerse por medio de un objeto de propiedad sino que son cubiertas por el patrimonio fluctuante (Ibídem, tomo 95, pp. 267-300). Ya que este patrimonio no está protegido como tal por el artículo 14 inciso primero LF contra intervenciones por la imposición de deberes pecuniarios, el artículo 14 inciso primero LF tampoco protege de la

${ }^{2}$ Tribunal Constitucional Federal, colección oficial de sentencias, tomo 4, pp. 7-17; tomo 6, pp. 290-298; tomo 8, pp. 274-330; tomo 10, pp. 89-116; tomo 10, pp. 354-371; tomo 11, pp. 105-126; tomo 14, pp. 221-241; tomo 19, pp. 119-128; tomo 23, pp. 288-315; tomo 26, pp. 327-338; tomo 27, pp. 111-131; tomo 28, pp. 119-142; tomo 29, pp. 402-413; tomo 30, pp. 250-271; tomo 38, pp. 61-102; tomo 45, pp. 272-296; tomo 65, pp. 196-209; tomo 70, pp. 219-230; tomo 74, pp. 129-148; tomo 78, pp. 214-230; tomo 81, pp. 108-122; tomo 89, pp. 24-61; tomo 91, pp. 207-220; tomo 95, pp. 267-300; cfr. también Kirchhof, VVDStRL, 39, 1981, p. 227. 
imposición estatal de prestaciones en dinero. Estas son vistas como una contribución objetiva cuya admisibilidad no se ve afectada por la garantía de la propiedad de la LF. De esa manera se defendía y se defiende la tesis de que el impuesto es una intervención en el patrimonio sin intervenir en un derecho de propiedad concreto (Layer, p. 63). Únicamente sería aplicable el derecho general de la personalidad del Artículo 2 inciso primero LF como derecho procedente cuando una conducta estatal no afecta el ámbito de protección de otro derecho fundamental específico.

Un punto de vista planteado sin una fundamentación detallada no se convierte ya en derecho objetivo y no gana en fuerza persuasiva porque sea repetida como dogma y sea denominada jurisprudencia reiterada (Seer, 1999, p. 1.282). La indicación común de que el artículo 14 inciso primero LF protege valores patrimoniales pero no el patrimonio como tal, no parece fundamentar por qué los impuestos intervienen en el ámbito de protección del artículo 14 LF. El déficit argumentativo resulta especialmente considerable porque aquí no se excluye un derecho fundamental cualquiera de la valoración de intervención tributaria sobre el patrimonio del contribuyente, sino que se trata precisamente del derecho fundamental central para la esfera patrimonial. Justamente este derecho se vaciaría de contenido frente a los medios más intensivos y duraderos de la afectación soberana sobre el patrimonio privado (Friauf, 1975, p. 361). Con seguridad, nadie consideraría que la recaudación de impuestos como tal es completamente irreconciliable con el artículo $14 \mathrm{LF}$ porque al contribuyente se le extraigan sumas de dinero de su patrimonio. A la inversa, sin embargo, no es necesario ni sería argumentable dogmáticamente negar por completo la relevancia de la garantía de propiedad para el derecho tributario. A causa de la especial estructura del derecho fundamental garantizado por el artículo 14 LF, su aplicación sobre las leyes tributarias implica ciertamente algunas dificultades, las cuales, no obstante, pueden ser solucionadas y en vista de la amplia vigencia del artículo 1 inciso tercero LF también tienen que ser solucionadas para la garantía de propiedad.

E1 Tribunal Constitucional Federal mismo ha reconocido que una jurisprudencia así le quitaría todo el significado a la protección de la propiedad ya que podría ser vaciado por los impuestos. Desde la sentencia de las rentas ajenas de 1962 en jurisprudencia reiterada se parte de que una ley tributaria excepcionalmente también puede vulnerar el derecho fundamental de propiedad, cuando los deberes pecuniarios representen una carga excesiva para el afectado e intervengan gravemente en sus relaciones patrimoniales 
(así llamado efecto de estrangulamiento o confiscación) $)^{3}$ Por medio de esta cláusula de exceso el Tribunal Constitucional Federal entiende la garantía de propiedad en casos extremos como una manifestación de la garantía de la libertad personal y ve en el artículo $14 \mathrm{LF}$ una protección por lo menos contra contribuciones excesivas. El Tribunal acepta con eso de manera condicionada el artículo 14 LF como escala de examen y concede que también la legislación tributaria puede entrar en el ámbito de protección de la garantía de propiedad (Friauf, 1970, p. 303).

Sin embargo, es una contradicción insuperable que el Tribunal constate en general que la imposición de deberes pecuniarios todavía no se incluye en la descripción típica del artículo 14 LF (Schenke, 1976, p. 1181; Spanner, 1967, p. 100; Friauf, 1970, p. 301). El Tribunal Constitucional Federal no considera con esta jurisprudencia la diferencia fundamental entre la relevancia general para los derechos fundamentales de una medida estatal, por una parte, y que sea contraria a la constitución a causa de una vulneración específica del derecho fundamental respectivo. Las intervenciones que de entrada no se ubican en el ámbito de protección de un derecho fundamental tampoco pueden ser medidas con respecto a ese derecho aun cuando la intervención sea de mayor intensidad y, en consecuencia, tampoco lo vulneran. Para esto se apunta a una diferenciación cuantitativa, a pesar de que solo con una variación de la situación fáctica se podría alcanzar otro resultado del examen de conformidad con un derecho fundamental. Así, en la limitación de la protección de la propiedad según el artículo $14 \mathrm{LF}$ para derechos de propiedad concretos no se clarifica por qué un impuesto debe ser inadmisible si no afecta ningún objeto de propiedad determinado pero representa una carga de tal grado para el patrimonio, que por ejemplo las relaciones patrimoniales se afectan de manera fundamental o considerable (Schmidt, 1980, p. 493). Si la recaudación de impuestos no afecta el ámbito de protección del artículo 14 inciso primero LF entonces la garantía de propiedad tampoco puede ser vulnerada con la superación de un determinado nivel de impuestos. Se determinaría el alcance del ámbito de protección por la calidad de la intervención si el artículo 14 inciso primero LF no protegiera el patrimonio como tal, pero una afectación especialmente intensiva del patrimonio constituyera una intervención en el ámbito de protección del derecho fundamental. Esta jurisprudencia es ilógica en sí misma. O bien el artículo $14 \mathrm{LF}$ no

${ }^{3}$ Tribunal Constitucional Federal, colección oficial de sentencias, tomo 14, pp. 221-241; tomo 19, pp. 119-128; tomo 19, pp. 253-267; tomo 23, pp. 288-314; tomo 26, pp. 32-338; tomo 27, pp. 111-131; tomo 29, pp. 402-413; tomo 30, pp. 250-271; tomo 36, pp. 383-400; tomo 37, pp. 121-131; tomo 38, pp. 61-102; tomo 63, pp. 312-327; tomo 67, pp. 70-88; tomo 70, pp. 219-230; tomo 77, pp. 308-339; tomo 78, pp. 214-230; tomo 78, pp. 232-243; tomo 82, pp. 159-190; tomo 87, pp. 153-169. 
puede tenerse como medida de examen y entonces en caso de impuestos excesivamente altos tampoco se puede recurrir a la garantía de propiedad, o los deberes pecuniarios también caen siempre dentro del ámbito de aplicación del artículo 14 LF (Jungnickl, p. 108). Respecto de la pregunta de si los impuestos caen en el ámbito de aplicación del artículo 14 LF, la vía que escoge el Tribunal Constitucional Federal, haciendo depender su juicio del monto de los impuestos es intransitable.

En parte de la doctrina se interpreta la jurisprudencia como si el Tribunal apuntara no a determinar "si" es posible la aplicación del artículo 14 inciso primero LF sino a determinar "qué tanto" (Kleen, 1980, p. 529; Schmidt, 1980, p. 490). La frase solo debe decir que un impuesto debe ser recaudado en el marco de la función social de la propiedad. Si bien la intervención tributaria afecta la libertad de propiedad, el derecho fundamental en principio no es afectado, ya que está cubierto por la reserva de regulación del artículo 14 inciso primero frase segunda LF (Papier, 1972, p. 484). Esta condicionalidad alternativa de la propiedad privada y de la financiación a través de impuestos requiere que el Tribunal Constitucional Federal constate que la garantía de propiedad del artículo $14 \mathrm{LF}$ no protege frente a la imposición de deberes de prestaciones monetarias. Cualquier otra opinión desconocería la diferencia entre la tipicidad y la antijuridicidad de una intervención en un derecho fundamental.

Recién en la decisión de la segunda sala del Tribunal Constitucional Federal del 18 de enero de 2006 se confirmó esta interpretación, por lo menos en parte, en tanto que la sala constató que en todo caso los impuestos a los ingresos y a la actividad industrial y comercial han de ser calificados como afectaciones de posiciones jurídicas concretas (Tribunal Constitucional Federal, NJW 2006, pp. 1.191-1.192). En todo caso, la segunda sala deja la pregunta abierta de si con esto se presenta una variación de la jurisprudencia del "estrangulamiento" afirmada por la primera sala (Ibídem, pp. 1.191-1.193).

\section{El significado del principio de proporcionalidad en la justificación de la carga tributaria}

\section{La aplicación del principio de proporcionalidad} a la garantía de propiedad

En la determinación del contenido y los límites de la propiedad, la discrecionalidad del legislador es limitada por el mandato de justa ponderación (Schwerdtfeger, 
p. 173; Benda, 1979, p. 467). El Tribunal Constitucional Federal reformula esto en términos de que para las regulaciones en el sentido del artículo 14 inciso primero frase segunda el legislador debe "tener en cuenta, en proporciones iguales, ambos elementos de la relación consagrada en la LF entre la posición jurídica garantizada constitucionalmente y el mandato de un ordenamiento socialmente justo de la propiedad"; el legislador tiene que "establecer una compensación justa y una relación balanceada entre los intereses dignos de protección de los intervinientes". „Una preferencia unilateral” no es conforme „con las ideas constitucionales de una propiedad privada vinculada con lo social"4.

La justa ponderación -en la determinación del contenido y los límites de la propiedad-significa especialmente el respeto al principio de proporcionalidad. Como figura central de la dogmática de la intervención en los derechos fundamentales y como "regla guía general" de toda acción estatal (Ibídem, tomo 23, pp. 127-133; tomo 38, pp. 348-368), este principio encuentra una aplicación irrestricta también para el artículo 14 LF. En todas las intervenciones estatales en la esfera de libertad del ciudadano debe considerarse el principio de proporcionalidad entre fines y medios como disposición material decisiva para el principio de Estado de Derecho. El principio, como requisito más importante para las limitaciones de derechos fundamentales, tiene una importancia extraordinaria (Sachs, 2003). Él exige una razón constitucionalmente legítima para la intervención legislativa, la idoneidad de la medida de intervención escogida, su necesidad en el sentido de la elección del medio menos invasivo, así como una relación equilibrada entre la gravedad de la intervención y el beneficio de la intervención, es decir, una proporcionalidad en la relación fin-propósito.

\section{Dudas sobre la efectividad del principio de proporcionalidad en la limitación de la recaudación de impuestos}

\section{a. La opinión dominante}

No obstante, precisamente para la intervención impositiva del Estado se cuestiona en la doctrina la efectividad del principio de proporcionalidad (Birk,

${ }^{4}$ Tribunal Constitucional Federal, colección oficial de sentencias, tomo 25, pp. 112-117; tomo 37, pp. 132-139; tomo 52, pp. 1-29; tomo 50, pp. 290-340; tomo 58, pp. 300-335; tomo 58, pp. 137-147; tomo 70, pp. 191-200; tomo 79, pp. 174-198; tomo 81, pp. 208-220; tomo 83, pp. 201-208; tomo 87, pp. 114-138; tomo 91, pp. 294-308. 
p. 187; Isensee, pp. 409-434; Papier, 1987, p. 74). Si el propósito determinante de la intervención consistiera en la obtención de ingresos, parece que estaría completamente descartado que en algún momento el monto de la carga tributaria estuviera fuera de proporción con los ingresos que se busca obtener y que la carga estuviera fuera de relación con los ingresos respectivos del Estado (Papier, 1987, p. 78). Por lo tanto, no sería posible una ponderación sustancial de la intervención y el beneficio. En vista del propósito de los ingresos, el medio de la recaudación de impuestos siempre sería idóneo; un impuesto conduciría necesariamente a la obtención de recursos y siempre sería necesario, ya que con respecto a la apropiación fiscal no existiría un medio que fuera menos gravoso para el ciudadano pero que sea igualmente efectivo (Ibídem, p. 76). En concordancia con esto se encuentra la jurisprudencia del Tribunal Constitucional Federal, según la cual en el ámbito de las leyes tributarias a diferencia de la mayoría de autorizaciones de intervención no puede producirse una relación entre el propósito de la intervención y el peso de la misma y por lo tanto realmente tampoco es posible un examen de proporcionalidad concreto en el sentido de una ponderación de los intereses respectivos (Tribunal Constitucional Federal, colección oficial de sentencias, tomo 63, pp. 343-367; ya parecido: tomo 6, pp. 55-80).

\section{b. Crítica a la opinión dominante}

Si la opinión dominante tuviera la razón, esto significaría que el mecanismo más importante de protección de la libertad del Estado de Derecho no sería aplicable frente a la intervención más intensiva y amplia (para el ciudadano que respeta la ley) en la libertad protegida por derechos fundamentales. No solo en virtud del principio del Estado de Derecho son procedentes las dudas sobre la opinión tradicional, también lo son en vista de la garantía de propiedad, con la cual (como hemos visto) debe medirse la imposición de deberes monetarios. Sin embargo, la pretensión de libertad fundamental del ciudadano frente a la intervención impositiva del Estado necesariamente tiene que traer hacia sí la validez del principio de proporcionalidad. Este principio es la condición más importante para la limitación de derechos fundamentales (Sachs, introducción artículo 1, número marginal 135 y artículo 20, número marginal 146). El concepto de ponderación es un requisito de una efectiva protección de la libertad por derechos fundamentales. El conflicto entre el interés de la dirección del Estado en una medida y el interés de la libertad del ciudadano solo puede ser resuelto en una 
ponderación valorativa; la ponderación de intereses y bienes es por tanto un instrumento irrenunciable de la protección de la libertad (Wendt, 1979, pp. 414-455). Por esto es difícilmente concebible que el principio de proporcionalidad no tenga validez para la materia impositiva (Wendt, 1987, pp. 1.257-1.260).

Si partimos de la base de que toda protección de la libertad por derechos fundamentales requiere necesariamente la ponderación de intereses y bienes en el examen de proporcionalidad (Tribunal Constitucional Federal, tomo 30, pp. 292316; Dechsling, 1989, p. 9), entonces realmente se plantea el problema expuesto por la doctrina dominante según el cual el propósito de la obtención de ingresos no permite en el caso concreto "una relación entre el propósito de la intervención y su gravedad [...] y por tal razón tampoco un examen de proporcionalidad concreto en el sentido de una ponderación de los intereses respectivos" (Ibídem, tomo 63, pp. 343-367). De esto, sin embargo, no necesariamente se debe extraer la conclusión de que se excluye la aplicabilidad del principio de prohibición de exceso para la tributación. Solamente se puede constatar que el principio de proporcionalidad no puede funcionar como mecanismo de protección del Estado de Derecho cuando en un extremo de la ponderación se ubique la "necesidad de financiación del Estado". ¿No es menos lógico concluir que el principio de proporcionalidad, tan importante para el Estado de Derecho, no logra hacer justicia a la naturaleza de la tributación, que concluir, a la inversa, que la utilización general de "la necesidad de recursos del Estado" no hace justicia a la naturaleza del principio de proporcionalidad en la necesaria ponderación de intereses?

El principio de proporcionalidad exige una medida de justicia con respecto a un objetivo determinado, requiere una adecuación entre los efectos gravosos de la acción estatal y el objetivo de la carga (Kirchhof, 1981, pp. 27-43). Por esto, el principio aprehende desde su contenido nuclear necesariamente los objetivos que él necesita para poder responder la pregunta que le es inmanente sobre la adecuación de una relación. Solo con una falta de sustancia de la libertad fundamental sería "inapropiada la pregunta sobre qué intereses públicos pueden justificar qué limitaciones de las garantías de libertad” (Wendt, 1979, pp. 414-459). Que la prohibición de exceso requiere en su funcionamiento objetivos concretos, examinables y relativizables y que por lo tanto el propósito abstracto de la obtención de ingresos no es idóneo como polo de la proporcionalidad, concuerda con la comprensión de que la obtención de ingresos del sector público no puede ser un fin en sí misma (Vogel, introducción artículo 104 a-115, número marginal 386). 


\section{Planteamientos para una reorientación que sea razonable para un Estado de Derecho}

a. Examen de proporcionalidad entre la carga tributaria y el peso de las erogaciones

Para examinar una intervención en un derecho lo más decisivo es establecer de la manera más concreta posible el propósito de la medida. Entre más concreto se pueda mencionar el propósito, más eficiente será el control de proporcionalidad (Vogel, 1981, p. 383). La financiación estatal como objetivo general de tributación no ofrece un motivo general para la legislación tributaria. El principio de proporcionalidad pierde de esa manera su fuerza expresiva como relación jurídica entre medios y fines (Kirchhof, 1981, p. 133). El juicio de la proporcionalidad de la carga tributaria requiere que también jurídicamente se mantenga en la mira la relación entre la recaudación de recursos tributarios y su utilización. Si se niega esto como la doctrina dominante en los términos anteriormente explicados, y se sigue apuntando al propósito superficial de la obtención de ingresos, el examen de proporcionalidad se convierte en una farsa y prescinde prácticamente de cualquier efecto de protección frente a los impuestos (Von Arnim, 1981, pp. 286-313).

De este análisis debe derivarse que la recaudación de impuestos para tareas públicas solo está justificada y es compatible con el artículo $14 \mathrm{LF}$ cuando ocurre en aras del bienestar de la generalidad. Esto requiere que las decisiones de política financiera se correspondan con el mandato de razonabilidad económica. Razonabilidad económica significa en esto la proporcionalidad entre la carga tributaria y el peso de las erogaciones y exige que los gastos menos urgentes todavía justifiquen los impuestos más gravosos (Ibídem, pp. 286-316). Las erogaciones son la línea de defensa sobre la que debe ubicarse la protección ante tributos excesivos del artículo 14 LF (Ibídem, pp. 286-317).

b. Falta de fuerza persuasiva de los argumentos contra la efectividad del principio de proporcionalidad

\section{Despilfarro de impuestos}

Como se sabe, una parte no despreciable de los ingresos tributarios es desperdiciada actualmente. La Federación de Contribuyentes Alemanes publica sobre 
esto anualmente un libro negro y reseña allí los casos más conocidos de despilfarro. Ahora, si en realidad se lleva a cabo un control de proporcionalidad en el que se ponga en relación directa la recaudación de recursos tributarios y su utilización, probablemente no habría impuestos que fueran conformes con la constitución a causa de este despilfarro. Ya que en vista del monto de la carga tributaria total y de la desproporcionada oposición al crecimiento del alto nivel de impuestos la intervención impositiva debe verse desproporcionada como consecuencia del despilfarro (solamente los informes del Tribunal Federal de Cuentas).

No obstante, la pregunta es si la "solución correcta" a este problema desde el punto de vista del derecho del Estado consiste en negarle al ciudadano, que es quien debe llevar la carga del despilfarro y del gasto indiscriminado de los recursos tributarios, la posibilidad de defensa ante la intervención fiscal sobre la base de los derechos de libertad y el principio de proporcionalidad. ¿Es realmente inapropiado que el contribuyente se oponga a las inocultables situaciones irregulares? ¿No es mucho más probable que la gestión financiera del gobierno debe parecer inaceptable?

En verdad debe parecer insostenible, en virtud del estado alcanzado por las finanzas públicas, que no deban existir posibilidades de control por el afectado en sus derechos del artículo $14 \mathrm{LF}$ con la recaudación de impuestos. Sería una paradoja negar el derecho de propiedad del contribuyente frente a la tributación excesiva con indicación al despilfarro público.

\section{Dispersión de impuestos}

La complejidad del sistema existente de muchos impuestos conduce a que la fijación de un límite máximo de carga se torne complicada (Tribunal Constitucional Federal, colección oficial de sentencias, tomo 93, p. 121). Sin embargo, cuestionar la existencia de una carga tributaria constitucional máxima a causa de esta problemática no resulta convincente. Puesto que el sistema vigente de muchos impuestos no debe ser defendido por los contribuyentes y tampoco puede ser usado para justificar un recorte de sus derechos. La complejidad del sistema fundamenta en buena medida la situación de amenaza para los derechos fundamentales del contribuyente. Esto se puede observar con especial claridad en comparación con un sistema de impuesto único. En la vigencia de un sistema tal se podría discriminar la carga impositiva de manera inequívoca en la carga justificada y la no justificada, a causa del despilfarro o de otras erogaciones desproporcionadas. 
¿Se justifica entonces despojar al ciudadano contribuyente de su posición jurídica de propiedad protegida por los derechos fundamentales porque en realidad tenemos un sistema tributario de muchos impuestos, no sistemático, escabroso y desde varios puntos de vista cuestionable? El sistema tributario existente es justamente el problema, es la amenaza a la libertad. Si su complejidad y fragmentación pudieran oponerse a los derechos fundamentales de defensa del contribuyente, entonces el legislador tributario podría liberarse de la observancia de los derechos fundamentales a través de estrategias de complejización. Por lo tanto, la relación constitucional entre la obtención de ingresos y el cumplimiento de tareas tampoco puede relajarse ni interrumpirse por el estado del derecho tributario positivo.

\section{El principio de "no afectación"}

Para la exclusión de la procedencia de propósitos de financiación concretos en la justificación de la intervención fiscal se argumenta, en especial, que conforme al principio de no afectación, todos los ingresos del Estado constituyen una masa unitaria, libre de vinculaciones con fines que cubren todas las erogaciones estatales. Por tal razón no es determinable si un determinado tributo es utilizado precisamente para tareas relativamente sin importancia (Von Arnim, 1981, pp. 286-314).

Sin embargo, esta argumentación debe ser refutada porque el principio de no afectación no tiene un rango constitucional (Kirchhof, 1984, p. 16). La no afectación debe excluir el cubrimiento preferente de erogaciones a través de ingresos vinculados con alguna finalidad, para impedir que las funciones públicas solo se cumplan para proveer de ingresos un propósito determinado. Representa así una instrucción a los encargados del presupuesto estatal que debe contribuir al aseguramiento del manejo económicamente razonable de los recursos tributarios ya recaudados. Afirmar el principio de no afectación contra el control de las finanzas por los derechos de libertad significaría convertirlo en su antítesis: en la medida en que aporta a oscurecer las relaciones entre decisiones de erogación y de imposición de cargas tributarias, se pervierte en un muro de protección detrás del cual se puede propagar el despilfarro público en perjuicio de todos los ciudadanos contribuyentes (Von Arnim, 1981, pp. 286-315). El principio de no afectación, con su rango y su contenido jurídicos no es apropiado para influir en la relación de derecho constitucional entre la obtención de ingresos y el cumplimiento de funciones. No puede conducir a una reducción de la protección de derechos fundamentales (Ibídem). 
Lo mismo rige para la intercambiabilidad real de los medios de cubrimiento que se encuentra en relación con esto. La incertidumbre sobre con qué medio monetario se financian cuáles tareas públicas por parte de que contribuyentes no puede debilitar la relación jurídica entre la intervención tributaria y los propósitos financiados. Por el contrario: precisamente porque los medios de cubrimiento son intercambiables no tiene importancia la objeción que se escucha con frecuencia en cuanto a que no se sabe adónde fluyen los recursos tributarios del afectado. La intervención tributaria transfiere el dominio sobre el patrimonio de los privados al sector público (Kirchhof, 1981, pp. 213-216). El hecho de que el potencial de acción requerido por el Estado e incorporado como fuerza de intercambio sea recaudado en forma líquida y estos medios monetarios sean intercambiables en vista de los fines perseguidos por el Estado con ellos, no puede oponerse a la exigencia de proporcionalidad derivada de los derechos de libertad. Más bien a causa de su intercambiabilidad se puede partir del hecho de que todo contribuyente aporta para toda tarea estatal en proporción respectiva a los volúmenes de las erogaciones entre sí. Justamente sobre esto se basa la posibilidad y la necesidad de una confrontación conforme a la cual la tarea estatal menos urgente tiene que poder justificar el impuesto más gravoso.

\section{El fallido intento de una concreción tributaria del principio de proporcionalidad: el principio de división por mitades}

a. La decisión sobre impuesto al patrimonio de la segunda sala del Tribunal Constitucional Federal

Bajo la dirección del entonces magistrado del Tribunal Constitucional Federal Paul Kirchhof, en junio de 1995 la segunda sala del Tribunal Constitucional Federal en su decisión sobre el impuesto al patrimonio derivó una limitación materializable del exceso de la carga tributaria más allá de la confiscación y del estrangulamiento de la propiedad. Según esto, la carga impositiva total de los ingresos (esperados) en una consideración típica de los ingresos, erogaciones deducibles y otras deducciones tiene que permanecer "cerca de una división por mitades entre el sector público y el privado” (Tribunal Constitucional Federal, tomo 93, pp. 121-138).. E1 Tribunal interpreta en esto el tenor literal de la función social de la propiedad según el artículo 14 inciso segundo frase segunda LF ("al mismo tiempo") de manera que 
la división (entre el beneficio privado y el beneficio común) debe producirse por partes "iguales". Dicho de manera sencilla, este así llamado principio de la división por mitades significa que los impuestos considerados en conjunto no deben superar más del $50 \%$ de los rendimientos del patrimonio.

\section{b. Reacción del Tribunal de Cuentas}

El Tribunal Federal de Cuentas (como tribunal supremo para asuntos de impuestos), a pesar de la decisión del Tribunal Constitucional Federal, ha persistido en el criterio según el cual el artículo 14 LF no contiene un mandato de limitar los impuestos a máximo un $50 \%$ del monto total de los ingresos o del patrimonio gravable (Tribunal Federal de Cuentas, DB, 1999, p. 2.291). La formulación "al mismo tiempo" contiene, según el uso generalizado del lenguaje y según el sentido literal de la palabra simplemente un elemento de tiempo e intención y no uno aritmético. Por lo tanto, de esto no se puede derivar un mandato para que la división de los ingresos se acerque a la mitad. Por medio de una interpretación tal se extendería el tenor literal, al que en una interpretación gramática solo puede concedérsele una coexistencia como "simultáneamente", pero no una igualdad abstracta (Jachmann, 1996, p. 103; Eschenbach, 1997, p. 414). La palabra no dice más que el uso de la propiedad y la función social tienen que ser puestos en equilibrio de manera proporcionada (Butzer, 1999, p. 76). El Tribunal Constitucional Federal simplemente quiso fijar un límite máximo aproximado pero no un principio de división por mitades (Sendler, 2000, p. 2.481).

Revisando los diccionarios de alemán esta argumentación puede contrarrestarse en tanto que el sentido de la expresión "al mismo tiempo" tiene el significado de las expresiones "de igual manera” (Duden, p. 1.084) y "por partes iguales" (Trübners, p. 49).

c. La "marcha atrás" de la segunda sala

Después de que también la primera sala del Tribunal Constitucional Federal se rehusara a seguir los argumentos del principio de división por mitades y simplemente confirmará la jurisprudencia del estrangulamiento de la propiedad (Tribunal Constitucional Federal, tomo 95, pp. 267-300), la segunda sala, en enero del 2006, dio marcha atrás y aclaró que, en su criterio, del artículo 14 LF no se puede derivar un límite máximo absoluto de la carga tributaria que se acerque a una distribución 
por mitades (Tribunal Constitucional Federal, NJW 2006, pp. 1.191-1.193). E1 principio de división por mitades se refiere "solo a las cargas que pueden establecerse como co-causantes de una carga fiscal al patrimonio, es decir, aquellas en las que el impuesto al patrimonio se suma a los demás impuestos" (Ibídem, pp. 1.191-1.192).

\section{Conclusiones}

No se aprecia una fundamentación convincente para una liberación de la tributación de la prohibición de exceso, el mecanismo de control más importante del Estado de Derecho. El Estado y los impuestos necesitan más que una justificación básica, general, pero no cuestionable en la práctica. Más bien, en vista de la necesidad cada vez más apremiante de limitar la desbordante actividad estatal, tiene que poder cuestionarse las tareas estatales individualmente consideradas y las cargas públicas que surgen de ellas por la posición pública de quien las financia. Debe ser posible plantear la pregunta sobre qué medida todavía se corresponden las tareas públicas desde el punto de vista de su carga financiera con el interés del ciudadano. Por tal razón, el legislador tiene que poder examinar cada decisión susceptible de consenso desde el punto de vista del nivel de impuestos alcanzado, ya que ningún cumplimiento de tareas disfruta de una prelación automática.

Todas las decisiones estatales han de ser comparadas y ponderadas unas frente a otras respecto de su valor y de las limitaciones a la libertad que van unidas a ellas. Esta es la consecuencia necesaria de que un Estado de Derecho no es libre para darse sus propias tareas. Tanto el Estado como tal, como el cumplimiento de las funciones de sus órganos son vistos, con razón, como susceptibles de ser fundamentados a causa de las limitaciones a la libertad que se producen necesariamente en el ejercicio de aquellas. Todo cumplimiento estatal de funciones requiere una justificación. Esta se encuentra dada solamente en la medida en que el cumplimiento de la función estatal se muestre como necesario. A los órganos legitimados democráticamente y por lo tanto llamados en primera línea a la formulación del bien común, se les ha conferido una prerrogativa de apreciación respecto de la necesidad de sus tareas y de las erogaciones relacionadas con ellas. Sin embargo, dicha prerrogativa es limitada y puede ser sobrepasada. Las preguntas como, ¿qué es (todavía) una tarea admisible?, y, ¿qué tan alta puede ser la intervención fiscal en su punto máximo? Solo pueden responderse en un proceso de la ponderación mutua, de mirar recíprocamente entre la obtención de ingresos y el cumplimiento de funciones. 
No obstante, el procedimiento de ponderación entre obtención de ganancias y el cumplimiento de tareas conduce no solo a manifestaciones respecto de la relación de la altura absoluta de la carga tributaria frente a la urgencia de la función estatal ejecutada en concreto. La ponderación muestra también que determinados efectos de la intervención tributaria, incluso frente a tareas estatales forzosas, deben ser clasificadas como desproporcionadas. Ya que la creación de fundamentos económicos de la vida por la sociedad es la condición de toda acción estatal, el efecto de un impuesto que impide inversiones y destruye empresas prácticamente no puede estar justificado desde el punto de vista de ningún propósito público.

El Estado y los impuestos no pueden ser un fin en sí mismo en el Estado de Derecho, ellos tampoco pueden justificarse por sí mismos ni por medio de una elevación metafísica. Si el propósito de financiación general permanece como "la medida de todas las cosas" para la justificación de la carga fiscal, surge la sospecha en el ciudadano de que la doctrina y la justificación de los impuestos no han dado por completo el paso hacia el Estado de Derecho.

Para la materialización de una justicia en el derecho tributario impregnada por el Estado de Derecho, el mandato de simetría en la tributación debe complementarse con una prohibición de exceso. Como derecho fundamental central de la esfera patrimonial la garantía de propiedad del artículo $14 \mathrm{LF}$ asume allí el papel protagónico. La garantía del beneficio privado de la propiedad y su función social tienen que constituir la medida central desde los derechos fundamentales, para la potestad impositiva del Estado. El derecho fundamental debe poder repeler intervenciones impositivas, debe poder exigir una renuncia al poder también en el derecho tributario y debe así mismo poder contribuir al desarrollo del principio de libertad en materia fiscal. Cada intervención tributaria sobre los bienes patrimoniales debe poder justificarse como menoscabo del beneficio privado de la propiedad. Este examen de justificación requiere una ponderación continuada entre la obtención de ingresos y el cumplimiento de funciones bajo una consideración constante del principio de proporcionalidad. Un recaudo de impuestos para la financiación de erogaciones que contrarían el principio de razonabilidad económica debe verse como innecesario, no sirve al bien común y es incompatible con el artículo 14 LF. El Estado solo puede imponer gravámenes al ciudadano en la medida en que esto sea indispensable para sus funciones irrenunciables en un orden económico y social liberal.

Sin embargo, estos esfuerzos jurídicos también están sometidos a límites. Puesto que los impuestos no solo son instrumentos de poder del Estado, también 
son ayudas del ciudadano al Estado y son con ello una expresión de la relación del ciudadano con su Estado. A través de los impuestos, el ciudadano financia al Estado, le permite participar de su éxito económico; materializa su libertad de generar beneficios económicos no solo para sí, sino también para el Estado. Bajo este aspecto se hace claro que los impuestos como auxilios obligatorios están sometidos igualmente a la difícil psicología de suministrar. El ciudadano solo aceptará los impuestos cuando tenga la sensación de que su aporte es justo. Sin embargo, este sentimiento de justicia está marcado por una posición política y se llena de una comprensión muy distinta del rol del Estado en la configuración del orden social. Siempre que el ideal de justicia toma una forma en un ciudadano, se produce en $e l$ otro el reproche de injusticia. Así, la justicia tributaria siempre tiene que ver con cómo se percibe la situación propia, con las comparaciones individuales. Las personas se sienten menos oprimidas por las cargas tributarias como tales que por la distribución inequitativa de las mismas. La ventaja probablemente injustificada de otra persona es percibida frecuentemente como más injusta que la carga tributaria. Y lo que es más extraño: la ventaja propia no es percibida como injusta, sino que se defiende en nombre de la justicia. El contribuyente mide con un rasero doble. Un régimen impositivo convincente desde el punto de vista del Estado de Derecho tampoco podrá en ningún momento afrontar correctamente este reto psicológico.

Por lo demás los mecanismos de configuración política también ganan significado con la pregunta acerca de la justicia tributaria. Una democracia que obtiene sus ingresos en la competencia internacional cada vez más a costa de la clase media de la sociedad, una política que no dispone de un tratamiento adecuado para las familias como comunidad especialmente protegida y que pone cargas a las generaciones futuras con obligaciones de pago exageradas pone en peligro la cohesión de su orden de libertad y pierde con ello de vista el objetivo de la justicia.

\section{Referencias}

Badura, P. (1974). Die Verfassung als Auftrag, Richtlinie und Grenze der wirtschafts- und arbeitspolitischen Gesetzgebung. En Revista WiR, 1. Editorial Athenäum.

Benda, E. (1979). Bundesverfassungsgericht und Gesetzgeber im dritten Jahrzehnt des Grundgesetzes. En Revista DÖV, 465. Editorial Kohlhammer.

Birk, D. (2011). Das ungerechte an der Steuergerechtigkeit. En Revista StuW, 354-364. Editorial Otto Schmidt. 
(1983). Das Leistungsfähigkeitsprinzip als Maßstab der Steuernorm. Editorial Deubner.

(2007). Das verfassungsrechtliche Maß steuerlicher Belastung. En Libro homenaje a Merten, 149. Editorial Müller.

. (1999). Das Geldeigentum. En Libro homenaje a Leisner. 635. Editorial Duncker und Humblot. . (1981). Besteuerung und Eigentum. Editorial C.H. Beck. (1993). Gleichmaß und Übermaß. En Libro homenaje a Lerche, 133. Editorial C.H. Beck.

Böckenförde, E. W. (1969). Entstehung und Wandel des Rechtsstaatsbegriffs. En Libro bomenaje a Adolf Arndt, 53. Editorial Europäische Verlagsanstalt.

Böhmer, W. (1988). Grundfragen der verfassungsrechtlichen Gewährleistung des Eigentums in der Rechtsprechung des Bundesverfassungsgerichts. En Revista NJW, 2.571. Editorial C.H. Beck.

Butzer, H. (1999). Freibeitsrechtliche Grenzen der Steuer-und Abgabenlast. Editorial Duncker \& Humblot.

Dechsling, R. (1989). Das Verbältnismäßigkeitsprinzip. Editorial Vahlen.

Depenheuer, O. (1999). Zwischen Verfassung und Gesetz. Die rechtsstaatliche Struktur der grundgesetzlichen Eigentumsgarantie. En Libro homenaje a Leisner, 278. Editorial Duncker und Humblot.

Di Fabio, U. (2007). Steuern und Gerechtigkeit. En Revista JZ, 749. Editorial Mohr Siebeck. Eschenbach, J. (1997). Steuerrecht und Eigentumsschutz. En Revista DStZ, 413. Editorial C.H. Beck.

Forsthoff, E. (1954). Begriff und Wesen des sozialen Rechtsstaates. Editorial C.H. Beck.

Friauf, K. H. (1980). Steuergesetzgebung und Eigentumsgarantie. En Revista DÖV, 482.

Editorial Kohlhammer.

Homburg, S. (20015). Allgemeine Steuerlebre. Séptima edición. Editorial Vahlen.

Isensee, J. (2009). Privatautonomie. En HStR VII, 150, 207. Editorial Müller. . (2011). Grundrechtsvoraussetzungen und Verfassungserwartungen an die Grundrechtsausübung. En HStR IX, 190, 265. Editorial Müller. . (1977). Steuerstaat und Staatsform. En Libro homenaje a Ipsen, Editorial Mohr. Kirchhof, P. (1984). Steuergleichheit. En Revista StuW, 297. Editorial Otto Schmidt. . (1975). Steuerrecht und Verfassungsrecht. En Revista DStZ, 360. Editorial C.H. Beck. . (1977). Substanzeingriff durch Steuer-Kumulation und Eigentumsgarantie. En Revista StuW, 59. Editorial Otto Schmidt. 
Lang, J., \& Klaus, V. (1996). Jahre. En Revista StuW, 67. Editorial Otto Schmidt. . (1997). Zur Rechtsreform des Steuerrechts. En Libro bomenaje a Kriele, 965. Editorial C.H. Beck.

Leisner, W. (1996). Verfassungsschranken der Unternehmensbelastungen. En Revista NJW, 1.511. Editorial C.H. Beck.

Lerche, P. (1999). Übermaß und Verfassungsrecht. Segunda edición. Keip Verlag.

Limpens, H. (1973). Funktion und Grenzen der Inbaltsbestimmung des Eigentums. Köln, Hochschulschrift.

Mußgnug, R. (1991): Verfassungsrechtlicher und gesetzlicher Schutz vor konfiskatorischen Steuern. En Revista JZ, 993. Editorial Mohr Siebeck.

Papier, K. (1987). El estado desenfrenado. Alemania.

Papier, H. J. (1980). Besteuerung und Eigentum. En Revista DVBI, 787. Editorial Carl Heymanns.

Pirnat, K. (1956). Dämon Steuer. Vienna. . (1973). Die finanzrechtlichen Gesetzesvorbehalte und das grundgesetzliche Demokratieprinzip. Editorial Duncker \& Humblot.

Rodi, M. (1994). Die Rechtfertigung von Steuern als Verfassungsproblem. Editorial C.H. Beck. Rüfner, W. (1970). Die Eigentumsgarantie als Grenze der Besteuerung. En Revista DVBI, 881. Editorial Carl Heymanns.

Rüthers, B. (2009). Das ungerechte an der Gerechtigkeit. Tercera edición. Editorial Mohr Siebeck.

Seillhorn, S. (2011). Steuersatz und Verfassungsrecht. En Steuer und Wirtschaft StuW, 88(4), 87. Alemania.

Schemmel, B. (1992). Dsi. Steuern. En Karl-Bräuer-Institut des Bundes der Steuerzabler, 75, 83. Alemania.

Schachtschneider, K. A. (1994). Res publica res populi. Editorial Duncker \& Humblot. . (1991). Das Recht am und das Recht auf Eigentum. En Libro homenaje a Leisner, 743. Editorial Duncker \& Humblot. (1996). Sozialistische Schulden nach der Revolution. Editorial Duncker \& Humblot.

Schenke, W. R. (1976). Besteuerung und Eigentumsgarantie. En Libro homenaje a Armbruster, 178. Editorial Editorial Duncker \& Humblot.

Schwerdtfeger, G. (1977). Optimale Methodik der Gesetzgebung als Verfassungspflicht. En Libro homenaje a Ipsen, 173. Editorial Mohr.

Seillhorn, T. (1997). Steuersatz und Verfassungsrecht. Editorial DUV. 
Sendler, H. (2000). Der Halbteilungsgrundsatz und die Etymologie. En Revista NJW, 2.481-2.482. Editorial C.H. Beck.

Spanner, H. (1967). Der Steuerbürger und das Bundesverfassungsgericht. Editorial Schmidt.

Tipke, K. (1995). Vermögen - und Erbschaftsteuer-Gerechtigkeit - Anmerkungen zu den BVerfG-Beschlüssen. En Revista MDR, 1.179. Editorial Otto Schmidt

Vogel, K. (1981). Verfassungsgrenzen für Steuern und Staatsaufgaben? En Libro homenaje a Maunz, 425. Editorial C.H. Beck. . (1991). Der offene Finanz- und Steuerstaat. Editorial Müller. . (1986). Rechtfertigung der Steuern - eine vergessene Vorfrage. En Revista Der Staat, 481. Editorial Duncker \& Humblot. . (1990). Grundzüge des Finanzrechts. En HStR, 87. Editorial Müller.

Von A., \& Hasn, H. (1981). Besteuerung und Eigentum. En VVDStRL, 39, 286. Editorial C.H. Beck.

Wendt, R. (1980). Besteuerung und Eigentum. En Revista NJW, 2.111. Editorial C.H. Beck. . (1979). Der Garantiegehalt der Grundrechte und das Übermaßverbot. En Revista AöR, 104, 414. Editorial Mohr Siebeck.

(1987). Zur Vereinbarkeit der Gewerbesteuer mit dem Gleichheitssatz und dem Prinzip der Besteuerung nach der Leistungsfähigkeit. En Revista BB, 1.257. Editorial dfv-Mediengruppe. 